\title{
Medication prescribing errors among hospitalized pediatric patients at Nekemte Referral Hospital, western Ethiopia: cross-sectional study
}

\author{
Ginenus Fekadu $^{{ }^{*}} \mathbb{D}$, Eba Abdisa ${ }^{2}$ and Korinan Fanta ${ }^{3}$
}

\begin{abstract}
Objective: Incidence and clinical outcomes of medication prescribing errors are common and potentially more harmful in the pediatric population than in the adult population. Hence, this study was aimed to assess the prevalence and types of medication prescribing errors in the pediatric wards of Nekemte Referral Hospital (NRH).

Results: Of 384 pediatric patients included in the study, 241 (63\%) were males and 116 (30.21\%) of them were aged between 1-3 years. About 241 (62.76\%) of the patients were treated based on empirical diagnosis and only 10 (2.60\%) pediatrics had co-morbid disease. The most category of medication prescribing error was dosing error 251 (48.6\%) followed by incorrect drug selection 98 (19.0\%). Being critically ill (AOR $=5.31,95 \% \mathrm{Cl}=1.80-12.31, p=0.003)$, route of administration via IV $(A O R=3.98,95 \% \mathrm{Cl}=1.85-11.15, \mathrm{p}=0.011)$ and via $\mathrm{IV}+\mathrm{IM}$ route $(\mathrm{AOR}=2.22,95 \% \mathrm{Cl}=1.05-$ $9.25, p=0.045$ ) as well as $4-6$ medications per patient $(A O R=3.10,95 \% \mathrm{Cl}=3.43-12.42, p=0.012$ ) and $>6$ medications per patient ( $A O R=7.23,95 \% \mathrm{Cl}=3.91-21.45, \mathrm{p}<0.001$ ) were independent predictors of medication prescribing errors. Antibiotics were the most common classes of drugs responsible for prescribing errors.
\end{abstract}

Keywords: Prescribing error, Pediatrics, Medications, Nekemte, Ethiopia

\section{Introduction}

Prescription is an instruction written from a prescriber to a drug dispenser $[1,2]$. It is considered as document that should be written clearly and accurately as well as should indicate precisely what should be given to patients [3]. There are two main categories of prescribing error; these are omission error (missing essential information) and commission error (addition of wrong information) [2]. Despite, medication prescribing error is a preventable event; its incidence and clinical effect were common among pediatric population. Compared to adults' pediatric population are sensitive to harmful consequences of medication prescribing error due to different factors such

\footnotetext{
*Correspondence: take828pharm@gmail.com;

ginenus@wollegauniversity.edu.et

${ }^{1}$ Clinical Pharmacy Unit, Department of Pharmacy, Institute of Health Sciences, Wollega University, Nekemte, Ethiopia

Full list of author information is available at the end of the article
}

as rapid physiological change, pharmacokinetic variations, organ maturity, variation in age and weight [3-9].

High medication error rates with significant consequences occur in intensive care units but errors could be minimized with intensive follow-up and appropriate monitoring of the medications [10]. Reviewing orders and prescriptions by pharmacists is critical step for detecting errors and preventing adverse impacts on patients [11, 12]. Adherence to basic prescription writing order delivers appropriate information to dispensers by delivering appropriate information for the treatment of patients. In contrary to this, failure to adhere to standard prescription writing order can cause drug-drug interaction, toxicity, exacerbation of the illness, and poor treatment outcomes that can lead to high economic crisis and lose of the patients' life [2]. Therefore, auditing prescription and assessing medication prescription errors are important to give appropriate feedback and to ensure rational prescribing among prescribers $[2,5]$. 
Data regarding pediatrics prescribing error in Ethiopian health setups is almost absent [8]. Therefore, this study was aimed to assess the prevalence and types of prescribing errors at pediatric wards of NRH.

\section{Main text}

Patients and methods

Study setting and study design

Institutional based cross sectional study was conducted at NRH from February to April 2017, Nekemte town, western Ethiopia.

\section{Eligibility criteria}

Pediatric patients admitted to NRH who had medication prescription were included irrespective of treatment outcome. While pediatric patients who were self-discharged and those $>12$ years of age were excluded from the study.

\section{Sample size and sampling technique}

Single population proportion formula was used to calculate sample size using the level of significance taken as $95 \%,(Z \alpha=1.96)$, error of margin $=5 \%$ and $\mathrm{P}$ was assumed to be $50 \%$. Accordingly, the minimum sample size was fixed to be 384 .

$$
\mathrm{n}=\frac{\frac{(Z \alpha)^{2}}{2} \mathrm{p}(1-\mathrm{p})}{\mathrm{d}^{2}}
$$

where, $\mathrm{p}=$ extent of adherence of prescribers to non-prescription error. $Z=$ critical value at $95 \% \mathrm{CI}$ of certainty (1.96). $d=$ the margin of error (5\%). $n=$ the required sample size.

Therefore, the sample size was

$$
\mathrm{n}=\frac{(1.96)^{2}(0.5)(1-0.5)}{(0.05)^{2}} \quad \mathrm{n}=384
$$

Random sampling technique was employed to select the study participants.

\section{Data collection process and quality assurance}

Semi-structured data collection tool was utilized to collect necessary data from patient cards and medication charts. Data quality was assured by careful selection and collection of complete data. The clarity and completeness of the data collection tool was checked before the actual data collection started. A 5\% sample pretest was performed on randomly selected patients at Gimbi General Hospital before the beginning of the study.

\section{Data processing and analysis}

The collected data was analyzed using SPSS version 20 . Prescribing errors were identified by comparing with
"National standard treatment guideline" and "Pocket book of pediatric hospital care in Ethiopia" [13-15]. Independent predictors of prescribing errors were analyzed using the logistic regression model by estimating the odds ratio (OR) and $95 \% \mathrm{CI}$ for each covariates. Confidence interval which doesn't contain 1 and predictor variables with probability value less than 0.05 was considered statistically significant.

\section{Results \\ Socio-demographic characteristics of patients}

Of a total of 384 pediatric patients included in the study, $241(63 \%)$ were males while the rest $143(37 \%)$ were females. About one-third of study participants (30.21\%) were between 1-3 years of age and infants consisted of 112 (29.17\%). Regarding the weight, one-third (33.33\%) of the patients weigh between 5.1 and $10 \mathrm{~kg}$ (Table 1).

\section{Diagnosis approaches used}

Out of 384 hospitalized pediatric patients, 241(62.76\%) were treated based on empirical diagnosis and 5(1.30\%) were treated based on laboratory tests/kinetic diagnosis. The remaining, 138(35.94\%) were treated based on both empirical and kinetic diagnosis.

\section{Clinical characteristics of the patients and medication prescribing errors}

During the study period, $10(2.60 \%)$ pediatrics had comorbid disease and about half of the patients (50.78\%) were severely ill. Out of a total study participants, 261 (67.97\%) of them had suffered from medication prescribing errors. The most category of medication prescribing error was dosing error 251 (48.6\%), followed by incorrect drug selection comprising 98 (19.0\%). Under dosing comprises of 198 (38.37\%) of the dosing errors. The medications which were not fully prescribed accounts $36(9.38 \%)$ while prescriptions with incorrect instructions comprises $10(2.60 \%)$. The sampled prescriptions contain a total of 1596 drugs. The average number of drugs per prescription was found to be 4.16 (Table 2).

\section{Predictors of prescribing errors}

After correction for other variables on multivariable logistic regression analysis severity of the disease, route of drug administration and number of medications per patient were strongly associated with medication errors at $\mathrm{p}<0.05$. Critically ill patients were almost 5 times more likely to have medication errors (ME) than patients who were acutely ill (AOR $=5.31,95 \%$ CI $1.80-12.31$, $\mathrm{p}=0.003)$. Patients who had administered medication via IV route were 4 times more to experience MEs compared to patients who had administered per oral $(\mathrm{AOR}=3.98,95 \%$ CI $1.85-11.15, \mathrm{p}=0.011)$. Patients 
Table 1 Socio demographic characteristics of pediatric patients admitted to pediatric wards of NRH, February 1 to April 30, 2017

\begin{tabular}{|c|c|c|c|}
\hline \multirow[t]{2}{*}{ Socio demographic characteristics } & \multicolumn{3}{|c|}{ Frequency and percentage } \\
\hline & Male & Female & Total \\
\hline \multicolumn{4}{|l|}{ Age } \\
\hline Infant (1-12 months) & $56(14.58 \%)$ & $56(14.58 \%)$ & $112(29.17 \%)$ \\
\hline Toddler ( $1-3$ years) & $80(20.83 \%)$ & $36(9.38 \%)$ & $116(30.21)$ \\
\hline Preschool (3-5 years) & $28(7.29 \%)$ & $36(9.38)$ & $64(16.67 \%)$ \\
\hline School age (5-10 years) & $51(13.28 \%)$ & $10(2.60 \%)$ & $61(15.88 \%)$ \\
\hline Adolescent (10-12 years) & $26(6.77 \%)$ & $5(1.30 \%)$ & $31(8.07 \%)$ \\
\hline Total & $241(62.75 \%)$ & $143(37.24 \%)$ & $384(100 \%)$ \\
\hline \multicolumn{4}{|l|}{ Body weight (kg) } \\
\hline$\leq 5.0$ & $20(5.21 \%)$ & $11(2.86 \%)$ & $31(8.07 \%)$ \\
\hline $5.1-10$ & $76(19.79 \%)$ & $52(13.54 \%)$ & $128(33.33 \%)$ \\
\hline $10.1-15$ & $60(15.635 \%)$ & $21(5.47 \%)$ & $81(21.1 \%)$ \\
\hline $15.1-20$ & $20(5.21 \%)$ & $16(4.16 \%)$ & $36(9.37 \%)$ \\
\hline$>20$ & $20(5.21 \%)$ & $6(1.56 \%)$ & $26(6.77 \%)$ \\
\hline Not recorded & $45(11.77 \%)$ & 37 (9.64\%) & $82(21.36)$ \\
\hline Total & $241(62.77 \%)$ & $143(37.24 \%)$ & $384(100 \%)$ \\
\hline
\end{tabular}

who had administered medication via IV + IM route were about 2 times more likely to experience MEs than patients who had administered per oral $(\mathrm{AOR}=2.22,95 \%$ CI $1.05-9.25, \mathrm{p}=0.045)$. Patients who had prescribed 4-6 medications concomitantly were 3 times more likely to have MEs than patients who had used 1-3 medications $(\mathrm{AOR}=3.10,95 \%$ CI 3.43-12.42, $\mathrm{p}=0.012)$, in the same way patients who had prescribed $>6$ medications concomitantly were about 7 times more likely to have MEs than patients who had used 1-3 medications $(\mathrm{AOR}=7.23,95 \%$ CI 3.91-21.45, $\mathrm{p}<0.001)$ (Table 3).

\section{Discussion}

This study was carried out with the aim of assessing the prevalence of medication prescribing errors in a resource limited setting particularly in Ethiopia. This study showed that $67.97 \%$ of pediatric patients had been exposed to at least one ME. Slightly comparable findings were reported from Dessie referral hospital [8], Nekemte referral hospital [15] and Jimma University specialized hospital [16] which reported that, $58.07 \%, 75.1 \%$ and $52.5 \%$ of the patients experienced at least one medication error, respectively. However, our finding was almost more than double compared to the study conducted in USA, where only $28.6 \%$ of patients had at least one ME [17].This difference could be due to differences in definitions of errors, methods used to detect errors, availability of facilities for patient care and role of pharmacist in the health care team. In current study, the sampled prescriptions contain a total of 1596 drugs. The average number of drugs per prescription paper was found to be 4.16. This was higher than the acceptable World Health Organization (WHO) ideal ranges (1.6-1.8) [18].

Pediatrics were prone to medication errors, predominantly because of the need for dosage calculations, which are individually based on the patient's weight, age, body surface area and their condition [17]. Dosing errors that includes selecting incorrect drug strength in pediatrics might lead to toxicity. Thus checking the drug, the dose, patient identity and any other relevant information before administering medicine is mandatory [19].

According to the present study the most frequent MEs was dosing error $48.64 \%$, which was in line with study done in Palestine were $40.0 \%$ of the medications were prescribed with one or more inappropriate doses [20]. However, our finding was higher compared to previous report from Nekemte referral hospital 23\% [15], Dessie Referral Hospital 31.39\% [8], Saudi Arabia 22.1\% [21] and two studies done in USA, $28 \%$ and $28.4 \%$ [17, 22]. Additionally, it was unlike to study done in Jimma University specialized Hospital where the most common type of medication prescribing error was the wrong combination of drugs (25.7\%) [16]. This discrepancy might be due to difference in completeness of data, hospital setup, medical condition of the patient and health care professionals' experience.

In this study antibiotics were the most common classes of drugs responsible for prescribing errors; which was in line with study conducted in United Kingdom, Jimma University specialized Hospital and Palestine [16, 20, 23]. 
Table 2 Clinical characteristics, prescribed medication and types of medication errors among pediatric patients admitted to pediatric wards of NRH, February 1, 2015-April 30, 2017

\begin{tabular}{|c|c|c|c|}
\hline Clinical characteristics & Frequency & Percentage (\%) & \\
\hline Had co- morbid disease & 10 & 2.60 & \\
\hline \multicolumn{4}{|c|}{ Severity of the disease (condition of the patient) } \\
\hline Acute & 51 & 13.28 & \\
\hline Severe & 195 & 50.78 & \\
\hline Critical & 138 & 35.94 & \\
\hline Previous medical history & 61 & 15.89 & \\
\hline Previous medication history & 51 & 13.28 & \\
\hline Previous hospital admission & 41 & 10.68 & \\
\hline Pediatrics with new cases & 323 & 84.11 & \\
\hline \multicolumn{4}{|l|}{ Number of medications per patient } \\
\hline $1-3$ & 112 & 29.17 & \\
\hline $4-6$ & 204 & 53.12 & \\
\hline$>6$ & 68 & 17.71 & \\
\hline Types of medication errors & Frequency & Percentage (\%) & \\
\hline \multicolumn{4}{|l|}{ Incorrect drug strength } \\
\hline Overdose & 53 & 10.27 & \\
\hline Under dose & 198 & 38.37 & \\
\hline Incorrect drug dosage & 98 & 19.0 & \\
\hline Drugs not fully prescribed & 87 & 16.86 & \\
\hline Incorrect drug selection & 48 & 9.3 & \\
\hline Drugs with incorrect instruction & 32 & 6.20 & \\
\hline Prescribed drugs & Route of administration & Frequency & Percentage (\%) \\
\hline Ceftriaxone & IV only & 257 & 22.13 \\
\hline Paracetamol & $\mathrm{PO}+$ Anal & 205 & 17.72 \\
\hline Gentamicin & $I M+I V$ & 189 & 16.34 \\
\hline Cephalexin & PO only & 118 & 10.19 \\
\hline Amoxicillin & PO only & 87 & 7.52 \\
\hline Cloxacillin & PO only & 72 & 6.22 \\
\hline Chloramphenicol & $I M+I V+P O$ & 67 & 5.79 \\
\hline Salbutamol syrup & $\mathrm{PO}$ only & 61 & 5.27 \\
\hline Ampicillin & $I M+I V+P O$ & 51 & 4.41 \\
\hline Hydrocortisone & IV only & 51 & 4.41 \\
\hline Total & & 1157 & 100 \\
\hline
\end{tabular}

$I V$ intravenous; IM intramuscular; $P O$ orally

Antimicrobial agents can be prescribed empirically without awaiting definite identification of the causative agent [24]. It was a great issue that only $1.3 \%$ of prescribed antibiotics were prescribed depending on the results of culture and sensitivity. This is mostly due to budget constraint and facility deficit in resource limited settings including our study hospital where it is not feasible to do culture and sensitivity test for each and every patients. The microbiological test is almost performed in our set up only for research and investigation purpose as well as in some cases when resistance is suspected.
With regard to predictors of medication prescribing errors; severity of the disease, routes of administration and number of medication per patient were found to be independent predictors of medication prescribing errors. Parenteral route was more likely associated with prescribing errors. This was in contrast with study done at Dessie Hospital revealing that intravenous route was less likely to be associated with prescribing errors [8]. Additionally, study by Dedefo et al. showed that route of administration was not shown to be a predictor of MEs in multivariable analysis $(p>0.05)$ [15]. But our finding 
Table 3 Multivariable analysis of factors associated with MEs among hospitalized pediatrics in pediatric wards of NRH, February 1, 2015-April 30, 2017

\begin{tabular}{|c|c|c|c|c|c|}
\hline Variables & Category & COR $(95 \% \mathrm{Cl})$ & $P$ value & AOR $(95 \% \mathrm{Cl})$ & $P$ value \\
\hline \multirow[t]{3}{*}{ Severity of the disease } & Acute & 1.00 & - & 1.00 & - \\
\hline & Severe & $2.27(1.63-6.56)$ & 0.002 & $1.21(0.52-4.24)$ & 0.087 \\
\hline & Critical & $6.12(2.40-11.81)$ & 0.001 & $5.31(1.80-12.31)$ & 0.003 \\
\hline \multirow[t]{6}{*}{ Routes of administration } & $\mathrm{PO}$ & 1.00 & - & 1.00 & - \\
\hline & IV & $4.46(2.53-12.57)$ & 0.000 & $3.98(1.85-11.15)$ & 0.011 \\
\hline & $\mathrm{IV}+\mathrm{IM}$ & $2.36(1.21-10.47)$ & 0.002 & $2.22(1.05-9.25)$ & 0.045 \\
\hline & $\mathrm{IV}+\mathrm{PO}$ & $2.10(0.98-4.10)$ & 0.070 & $0.83(0.55-2.55)$ & 0.978 \\
\hline & $\mathrm{PO}+$ anal & $1.98(0.29-4.57)$ & 0.084 & $1.34(0.20-3.80)$ & 0.531 \\
\hline & Others & $0.65(0.89-8.14)$ & 0.655 & $0.35(0.67-7.65)$ & 0.884 \\
\hline \multirow[t]{3}{*}{ Number of medications per patient } & $1-3$ & 1.00 & - & 1.00 & - \\
\hline & $4-6$ & $3.14(4.63-11.67)$ & 0.000 & $3.10(3.43-12.42)$ & 0.012 \\
\hline & $>6$ & $7.65(4.43-18.67)$ & 0.0001 & $7.23(3.91-21.45)$ & 0.000 \\
\hline
\end{tabular}

AOR adjusted odds ratio; COR crude odds ratio; $I V$ intravenous; $I M$ intramuscular; $P O$ oral

complies with study done in Saudi Arabia and Palestine where intravenous route (IV) has been reported as the most common causes of medication errors in children admitted to hospitals [20, 21]. This might be because parenteral route of administration is the most common route of drug administration for hospitalized pediatric patients.

Severity of the disease was one independent predictor of prescribing errors. As severity of the disease increases the number of medications used and errors also promptly increases. As the number and severity of disease increases, the number of medications required to treat conditions of the patient also increases. The present study showed that the number of medications used by the patient was significantly associated $(\mathrm{p}<0.05)$ with MEs and it was one of the independent predictors of MEs. This was in-line with previous study done in NRH [15] reporting that the more medications a patient is consuming, the more likely for the occurrence of MEs.

\section{Conclusion}

The study revealed that the prevalence of medication prescribing errors was high in pediatric wards of NRH. Severity of the disease, routes of administration and number of medication per patient were found to be independent predictors of medication prescribing errors. Antibiotics were the most common class of drugs involved in medication prescribing errors.

\section{Limitation of the study}

Given the cross-sectional study design was employed, it was not possible to establish causal relationships due to the lack of a temporal link. Additionally, incomplete information from patient's medical cards was also another issue. Finally, since the study included patients admitted to a single hospital, generalization of findings must be made cautiously.

\section{Abbreviations}

FMHACA: Food, Medicine and Healthcare Administration and Control Authority; ME: Medication error; NRH: Nekemte Referral Hospital.

\section{Acknowledgements}

We like to thank Wollega University, Department of pharmacy for logistic support. Additionally we thank NRH pediatric wards health care professionals and data collectors for the success of the study.

\section{Authors' contributions}

GF contributes in the design of the study, analysis, interpretation and write up of the manuscript. EB made the data analysis and interpretation of the data. KF contributed to the design of the study and edition of the manuscript. All authors read and approved the final manuscript.

Funding

None.

Availability of data and materials

The datasets used and/or analyzed during the current study are available from the corresponding author on reasonable request.

\section{Ethics approval and consent to participate}

Ethical clearance was obtained from ethical review board (ERB) of Pharmacy department of Wollega University with clearance reference number of PD/18/2017. The data was handled with strong confidentiality. The privacy of patients were secured by removing identifiers from data collection tools using different codes.

\section{Consent for publication}

Not applicable.

\section{Competing interests}

The authors declare that they have no competing interests.

\section{Author details}

${ }^{1}$ Clinical Pharmacy Unit, Department of Pharmacy, Institute of Health Sciences, Wollega University, Nekemte, Ethiopia. ${ }^{2}$ Department of Psychiatry, 
School of Nursing and Midwifery, Institute of Health Sciences, Wollega University, Nekemte, Ethiopia. ${ }^{3}$ Clinical Pharmacy Unit, School of Pharmacy, Institute of Health, Jimma University, Jimma, Ethiopia.

Received: 22 February 2019 Accepted: 9 July 2019

Published online: 16 July 2019

\section{References}

1. Yamana MN, Zamzamb R, Mohamada N, Nasri M, Besara A, Kamarudina MA. Evaluation of case write-up: Assessment of prescription writing skills of fifth year medical students at UKM Medical Centre. Procedia Soc Behav Sci. 2012;60:249-53.

2. Kozer E, Scolnik D, Macpherson A, Keays T, Shi K, LukT, Koren G. Variables associated with medication errors in pediatric emergency medicine. Pediatric. 2002;110(4):737-42.

3. Ferner RE. The epidemiology of medication errors: the methodological difficulties. Br J Clin Pharmacol. 2009;67(6):614-20.

4. Kozer E, Berkovitch M, Koten G. Medication errors in children. Pediatr Clin N Am. 2006;53:1155-68.

5. Otero P, Leyton A, Mariani G, Ceriani Cernadas JM. Medication errors in pediatric inpatients: prevalence and results of a prevention program. Pediatrics. 2008:122(3):e737-43.

6. Tully MP, Ashcroft DM, Dornan T, Lewis PJ, Taylor D, Wass V. The causes of and factors associated with prescribing errors in hospital inpatients: a systematic review. Drug Saf. 2009;32(10):819-36.

7. King WJ, Paice N, Rangrej J, Forestell GJ, Swartz R. The effect of computerized physician order entry on medication errors and adverse in pediatric inpatients. Pediatric. 2003;112:506-9.

8. Zeleke A, Chanie T, Woldie M. Medication prescribing errors and associated factors at the pediatric wards of Dessie Referral Hospital, Northeast Ethiopia. Int Archiv Med. 2014;7:18

9. Phillips J, Beam S, Brinker A, Holquist C, Honig P, Lee LY, Pamer C. Retrospective analysis of mortalities associated with medication errors. Am J Health System Pharm. 2001;58(19):1835-41.

10. ICU physician staffing. Fact sheet. The Leapfrog group for patient safety rewarding higher standards. http://www.leapfroggroup.Org/media/file/ FactSheet_IPS.pdf. Accessed Mar 122017.

11. Lesar TS, Mitchell A, Sommo P. Medication Safety in Critically III Children. Clin Pediatr Emerg Med. 2006;7(4):215-25.

12. Ghaleb MA, Barber N, Franklin BD, Yeung VW, Khaki ZF, Wong IC. Systematic review of medication errors in pediatric patients. The annals of pharmacotherapy. 2006;40:1766-76.
13. Food, Medicine and Healthcare Administration and Control Authority (FMHACA). Manual for medicines good prescribing practice. Addis Ababa: Food, Medicine and Healthcare Administration and Control Authority (FMHACA); 2012.

14. Food, Medicine and Healthcare Administration and Control Authority (FMHACA). Standard Treatment Guidelines for general hospitals. 3rd ed. Addis Ababa: Food, Medicine and Healthcare Administration and Control Authority (FMHACA); 2014.

15. Dedefo MG, Mitike AH, Mulugeta Tarekegn Angamo MT. Incidence and determinants of medication errors and adverse drug events among hospitalized children in West Ethiopia. BMC Pediatrics. 2016;16:81.

16. Agalu A, Ayele Y, Bedada W, Woldie M. Medication prescribing errors in the intensive care unit of Jimma University specialized Hospital, southwest Ethiopia. J Multidiscip Healthc. 2011:4:377-82.

17. Kaushal R, Bates DW, Landrigan C, McKenna KJ, Clapp MD, Federico F, Goldmann DA. Medication errors and adverse drug events in pediatric inpatients. JAMA. 2001;285:2114-20.

18. World Health Organization/Management Science for Health. A practical guide for Drug and Therapeutic Committee. Smithland: Geneva; 2003. p. 23-7.

19. Wong ICK, Wong LYL, Cranswick NE. Minimizing medication errors in children. Archiv Dis Childhood. 2009;94:161-4.

20. Al-Ramahi R, Hmedat B, Alnjajrah E, Manasrah I, Radwan I, Alkhatib M. Medication dosing errors and associated factors in hospitalized pediatric patients from the South Area of the West Bank—Palestine. Saudi Pharm J. 2017;25:857-60.

21. Al- Jeraisy MI, Alanazi MQ, Abolfotouh MA. Medication prescribing errors in a pediatric inpatient tertiary care setting in Saudi Arabia. BMC Res Notes. 2011;4:294-9.

22. Fortescue EB, Kaushal R, Landrigan CP, McKenna KJ, Clapp MD, Federico F, Goldmann DA, Bates DW. Prioritizing strategies for preventing medication errors and adverse drug events in pediatric inpatients. Pediatrics. 2003;111:722-9.

23. Ghaleb MA, Barber N, Franklin BD, Wong ICK. The incidence and nature of prescribing and medication administration errors in pediatric inpatients. Arch Dis Child. 2010;95:113-8.

24. Yewale VN, Dharmapalan D. Promoting appropriate use of drugs in children. In J Pediatrics. 2012;10:9065-70.

\section{Publisher's Note}

Springer Nature remains neutral with regard to jurisdictional claims in published maps and institutional affiliations.
Ready to submit your research? Choose BMC and benefit from:

- fast, convenient online submission

- thorough peer review by experienced researchers in your field

- rapid publication on acceptance

- support for research data, including large and complex data types

- gold Open Access which fosters wider collaboration and increased citations

- maximum visibility for your research: over $100 \mathrm{M}$ website views per year

At BMC, research is always in progress.

Learn more biomedcentral.com/submissions 